\title{
Prevalence of Anaemia among Pregnant Women in Braithwaite Memorial Specialist Hospital (BMSH) Port Harcourt
}

\author{
Elemchukwu Queen ${ }^{1}$,Obeagu Emmanuel Ifeanyi ${ }^{2}$ and Ochei Kingsley \\ Chinedum ${ }^{3}$ \\ 1.Rivers State College of Health Science and Technology, Port Harcourt. \\ 2.Diagnostic Laboratory Unit,Deparment of Health Services, Michael Okpara University of \\ Agriculture,Umudike, Abia State, Nigeria. \\ 3. Department of Medical Laboratory Sciences, Faculty of Basic Medicine, Ambrose Ali University Ekpoma, \\ Edo State, Nigeria.
}

\begin{abstract}
To assess the prevalence of anaemia in pregnancy and recommend a cut-off value for antenatal women in developing countries, a cross sectional study was carried out in the Braithwaite Memorial Specialist Hospital (BMSH), Port Harcourt, a tertiary health care centre in Nigeria. 346 apparently healthy asymptomatic pregnant women visiting the antenatal clinic for the first time were enrolled for the study. Hemoglobin concentrations were determined using standard hematological procedures. Out of the 346 pregnant women studied, 50 (14.5\%) were non-anaemic and 296 (85.5\%) were anaemic giving a prevalence rate of $85.5 \%$. There is moderate prevalence of anaemia in pregnancy in this part of the world. Since the mean Hb value of the pregnant women in this study was $11.25 \mathrm{gldl}$ and the pregnant women with $\mathrm{Hb}$ values around $10 \mathrm{gldl}$ are apparently healthy, a cut-off value of 10.0gldl may be considered ideal for defining anaemia in developing countries.
\end{abstract}

Keywords: Anemia, Pregnancy, non-anaemic, antenatal and heamoglobin concentration.

\section{Introduction}

Anaemia in pregnancy remains one of the most intractable public health problems in developing countries. It is extremely common and although not always shown to have a causal link, severe anaemia contributes to maternal morbidity and mortality (Usanga et al., 1994). Anaemia, even when mild to moderate affects the sense of well-being resulting in fatigue, stress and reduced work productivity. During labour, women with severe anaemia are less able to endure moderate blood loss and as a consequence are at a higher risk of requiring a blood transfusion during delivering, thus exposing patients unnecessarily to the risk of infection with human immunodeficiency virus (HIV) and other blood borne pathogens (Zucker et al., 1994).

It is estimated that anaemia may be responsible for as much as $20 \%$ of all maternal deaths in SubSahara Africa through three main mechanisms. Firstly, anaemia makes women more susceptible to deaths from haemorrhage by lowering their haematological reserves for blood loss especially at birth. Severe anaemia is associated with increased susceptibility to infection due to lowered resistance to disease, and $\mathrm{Hb}<4 \mathrm{gldl}$ is also associated with high risk of cardiac failure, particularly during delivering or soon after, making the woman likely to die if unable to reach good health facilities immediately (Rose et al., 1996).

Several studies have shown an association between anaemia and maternal morbidity from both hospital data and community based studies. In addition, severe maternal anaemia may impair the oxygen delivery to the fetus and interfere in normal intra-uterine growth, resulting in intra-uterine growth retardation, still birth, low birth weight and neonatal deaths (Axemo et al., 1995).

\section{AIMS OF THE STUDY}

This study aims at providing the prevalent statistics of anaemia in pregnancy and to access the effectiveness of antenatal care in preventing anaemia in pregnant women in Rivers State, Nigeria.

\section{OBJECTIVE OF THE STUDY}

The objective of this study is to determine the prevalence of anaemia in pregnant women attending antennal care at the Braithwaite Memorial Specialist Hospital (BMSH) Port Harcourt.

\section{SIGNIFICANCE OF THE STUDY}

This research work was carried out in order to broaden the knowledge of the laboratory personnels and other health practitioners and the pregnant women about the anaemia and the risk factors associated with it during pregnancy.

This research work is also vital as it will advance our knowledge on the signs and symptoms and the possible risks associated with this disease condition in relation to the reduction of blood level, fatigue, and little 
energy to work, breathless on exertion, palpitations, headaches and dizziness. There is also pallor of the skin, mucus membrane and conjunctiva, difficulty in concentrating and learning.

With these following symptoms coupled with the determination of haemoglobin level, one can actually know if he/she is anaemic and prophylactic measures will be taken to prevent the risk factors associated with it.

\section{RESEARCH DESIGN}

\section{Materials And Method}

A cross-sectional study was used.

RESEARCH SETTING

The study was conducted at the Braithwaite Memorial Specialist Hospital (BMSH), Port Harcourt, a government tertiary health care centre. Port Harcourt is a cosmopolitan city with a population of about 2 million inhabitants. It is the state capital of Rivers State and Nigeria's second largest commercial and industrial centre and has the second busiest seaport in Nigeria. Thus, apart from the indigenes, there are various ethnic groups living in Port Harcourt. The subject therefore represents subgroups of Nigerian pregnant women.

\section{STUDY POPULATION}

The study population consisted of 346 apparently healthy pregnant women residing in Port Harcourt, Rivers State, Nigeria who visited the antenatal clinic of the Braithwaite Memorial Specialist Hospital (BMSH), Port Harcourt between April and May 2013 for the first time. They were aged 15-48 years with differing gestational age and parity.

All subjects were offered confidential counseling and thereafter informed consent was obtained for blood sample collection. Information on demographic data, maternal age, gestational age, parity, history of previous transfusion and surgery and educational background as well as socioeconomic status were obtained from all subjects through questionnaire.

\section{COLLECTION OF BLOOD SAMPLE}

\section{Methodology}

A standard clean venipuncture techniques was used to collect $4 \mathrm{mls}$ of blood from each subject from the antecubital vein between $9.00 \mathrm{am}$ and 12.00 noon, of which it was dispensed into an EDTA anticoagulated tube. Blood samples were collected before the subjects were prescribed haematinics and antimalarial drugs as part of their antenatal prophylaxis. The anticoagulated samples were used for the determination of haemoglobin concentration.

\section{LABORATORY ASSESSMENT OF HAEMATOLOGICAL PARAMETER}

Haemoglobin concentration was determined by the haemocue method as described by Monica Cheesbrough and as recommended by the international committee for standardization in Haematology (ICSH) and World Health Organization (WHO).

\section{HAEMOCUE HAEMOGLOBIN TECHNIQUE}

The haemocue $\mathrm{Hb} 301$ haemoglobin meter is a point-of-care, easy to use portable meter that has been developed particularly for use in tropical countries. Unlike other Haemocue meters which measure haemoglobin in lysed blood using microcuvettes containing reagents sensitive to the effects of heat and humidity, the Hemocue $\mathrm{Hb} 301$ is designed to measure haemoglobin in untreated whole blood using microcuvettes that contain no reagents other than a surfactant to facilitate the entry of blood into the microcuvette. Capillary or EDTA anticoagulated venous blood can be used.

\section{PROCEDURE}

Pull the cuvette holder out to its loading position, press and hold down the botton until the display is activated. The meter automatically carries out a performance check. After approximately 10 seconds, the meter display shows three flashing dashes, indicating it is ready for use. In one continuous process, fill a Hemocue $\mathrm{Hb}$ 301 microcuvette with capillary blood or well-mixed venous blood (about $10 \mu 1$ of blood is required). Wipe off excess blood from the outside of the microcuvette, taking care not to withdraw blood from the tip. Immediately place the microcuvette in the cuvette holder (within 40 seconds of filling the mocrocuvette). Gently touch the cuvette holder. It will automatically slide to its measuring position.

After approximately 10 seconds the haemoglobin value will be displayed in gldl.

\section{DATA ANALYSIS}

Data was presented using descriptive statistics for anaemia among pregnant women. The prevalence for anaemic pregnant women was calculated using anaemic patients as numerator and the total number of pregnant women enrolled in the study as denominator. The data was also presented in scores, tables, histograms and analyzed using simple percentage 


\section{Results}

Table 1: Characteristics Of All Pregnant Women Studied According To Their Age Group

A total of 346 pregnant women aged 15-48 years were studied with haemoglobin $\mathrm{Hb}$ concentration ranged from $4.7 \mathrm{gldl}$ to $13.5 \mathrm{gldl}$. 296 of the pregnant women had haemoglobin values less than $11.0 \mathrm{gldl}(\mathrm{Hb}<$ $11.0 \mathrm{gldl}$ ) representing $85.5 \%$ of prevalence rate. The 296 anaemic pregnant women constituted the sub-sample study population for the aetiological assessment, while the remaining 50 non-anaemic pregnant women constituted the control group. The mean $\mathrm{Hb}$ concentration of $12.8 \mathrm{gldl}$ for the non-anaemic pregnant women was significantly higher than that of the mean of $\mathrm{Hb}<11.0 \mathrm{gldl}$ recorded for the anaemic pregnant women.

\section{AGE GROUP NUMBER HB $<11.0$ HB $>11.0$ FREQUENCY FREQUENCY

TESTED $\quad \mathrm{g} / \mathrm{dl} \quad \mathrm{g} / \mathrm{dl} \quad(\%) \mathrm{Hb}<11.0 \mathrm{~g} / \mathrm{dl}(\%) \mathrm{Hb}>11.0 \mathrm{~g} / \mathrm{dl}$

$\begin{array}{lrlllc}15-19 & 23 & 19 & 4 & 5.4 & 1.15 \\ 20-24 & 36 & 32 & 4 & 9.2 & 1.15 \\ 25-29 & 91 & 79 & 12 & 22.8 & 3.5 \\ 30-34 & 105 & 91 & 14 & 26.3 & 4.0 \\ 35-39 & 56 & 47 & 9 & 13.5 & 2.6 \\ 40-44 & 23 & 18 & 5 & 5.2 & 1.4 \\ 45-49 & 12 & 10 & 2 & 2.9 & 0.57 \\ \text { TOTAL } & \mathbf{3 4 6} & \mathbf{2 9 6} & \mathbf{5 0} & \mathbf{8 5 . 5} & \mathbf{1 4 . 3 7}\end{array}$

Table 2: Characteristics Of The Anaemic Pregnant

Women According To Trimester, Parity And Cut-Off $\mathrm{Hb}<11.0 \mathrm{~g} / \mathrm{Dl}$.

Out of 346 pregnant women studied 78 (19.9\%) were in their first trimester of gestation, $126(30.9 \%)$ for second trimester and $142(34.6 \%)$ for third trimester.

Parity ranged from $0-9,53(11.5 \%)$ were pregnant for the first time (primigravida), 96 (21.09\%) had one child each (primipara) and 197 (52.8\%) had two children and above (multigravida).

$\begin{array}{lccc}\text { TRIMESTERS } & \text { NUMBER TESTED } & \text { HB }<\mathbf{1 1 . 0 g / d l} & \text { FREQUENCY \% } \\ 1^{\text {st }} \text { trimester } & 78 & 69 & 19.9 \\ 2^{\text {nd }} \text { trimester } & 126 & 107 & 30.9 \\ 3^{\text {rd }} \text { trimester } & 142 & 120 & 34.6 \\ \text { PARITY } & & & \\ \text { Primigravida } & 53 & 40 & 11.5 \\ \text { Primipara } & 96 & 73 & 21.09 \\ \text { Multigravida } & 197 & 183 & 52.8\end{array}$

Table 3: Distribution Of Anaemic Pregnant Women According To Severity Of Anaemia

The distribution of anaemic pregnant women according to severity of anaemia based on $\mathrm{Hb}<11 \mathrm{gldl}$ cut-off as shown in the table above. Out of $296(85.5 \%)$ anaemia pregnant women, 128 (36.9) were mild anaemic, 116 $(33.5 \%)$ for moderately anaemic and $52(15.0 \%)$ for severely anaemic.

$\begin{array}{llll}\text { DEGREE } & \text { RANGE } & \text { FREQUENCY } & \mathbf{\%} \\ \text { Mild } & 9.0-10.0 & 128 & 36.9 \\ \text { Moderate } & 7.0-8.9 & 116 & 33.5 \\ \text { Severe } & <7.0 & 52 & 15.0\end{array}$


Figure 1: Graph Showing Frequency For Different Results And Different Age Ranges.

$$
120
$$

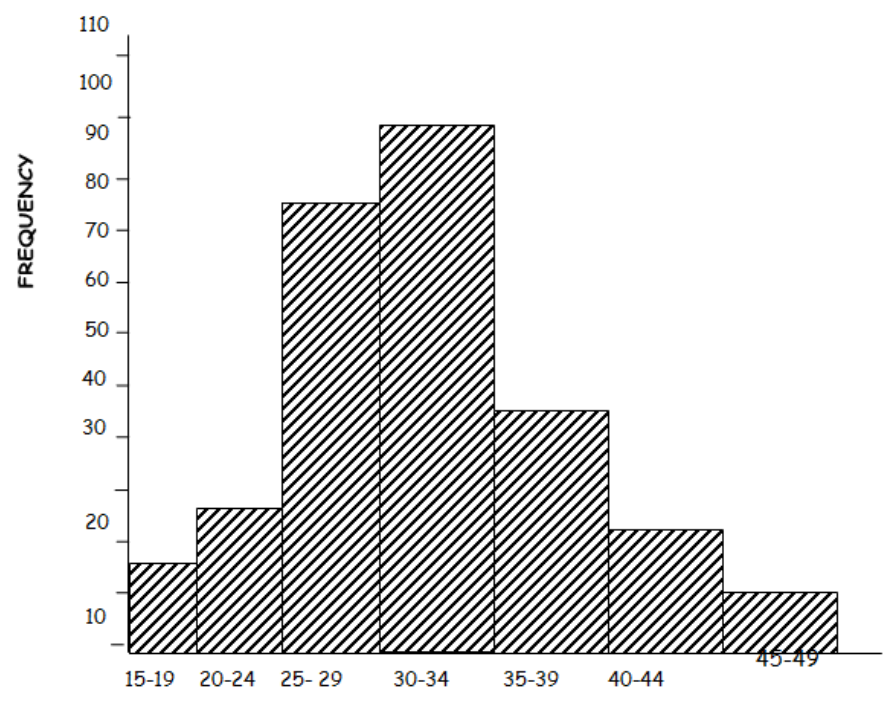

\section{AGE RANGE}

This graph shows the total number of pregnant women studied. It shows that the age range of 30-34 have the highest frequency and the least frequency within the age range of 45-49.

Figure 2: Graph Showing Frequency For Different Results At Different Trimesters.

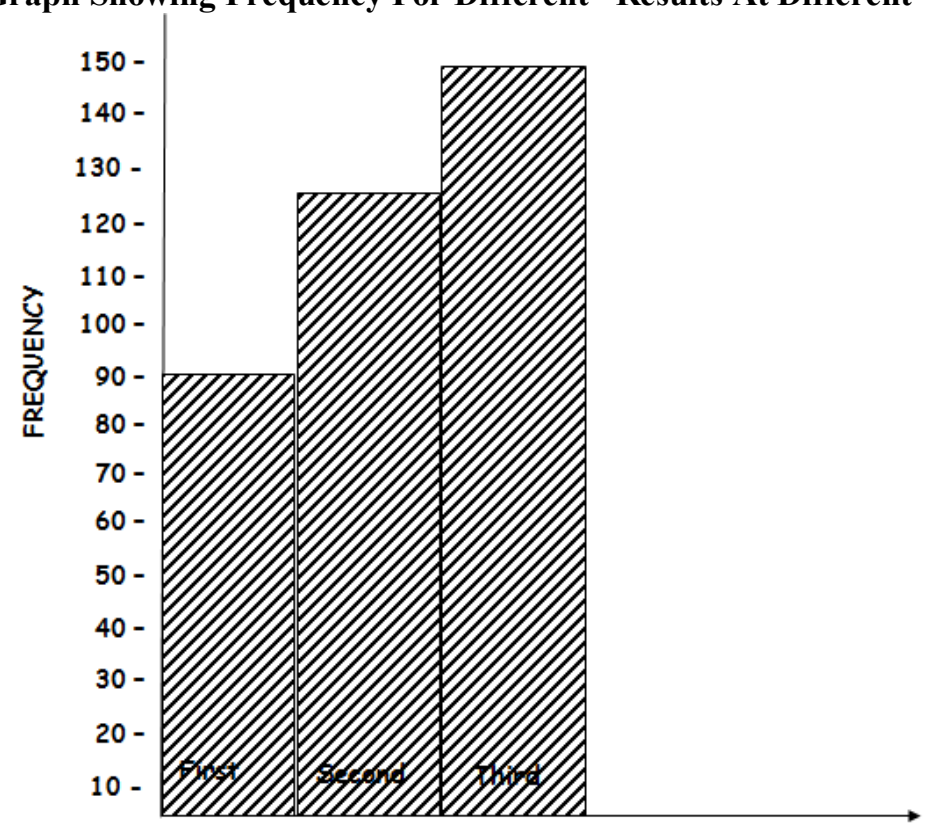

\section{TRIMESTERS}

The graph above shows the frequency distribution among the pregnant women based on trimesters. Out of 346 pregnant women studied, $78(19.9 \%)$ were in their first trimester, $126(30.9 \%)$ for second trimester and $142(34.6 \%)$ for third trimester with the highest prevalence rate.

\section{Discussion}

According to WHO standards, anaemia in pregnancy is present when the haemoglobin concentration in the peripheral blood is less than 11.0gldl. Anaemia, $(\mathrm{Hb}<11.0 \mathrm{gldl})$ was found to be present in $85.5 \%$ of the pregnant women in this study, of which 128 (36.9\%) had mild anaemia (Hb 9-10gldl), $116(33.5 \%)$ had moderate anaemia $(\mathrm{Hb} 7.0-8.9 \mathrm{gldl})$ and $52(15.0 \%)$ had severe anaemia $(\mathrm{Hb}<7.0 \mathrm{gldl})$. This finding is contrary to the $79.1 \%$ overall prevalence found among pregnant first-time attendees in Calabar (Usanga et al., 1994). It is also higher than the $29 \%$ prevalence reported by Aluka et al., (2001) in Aba, Nigeria. For the fact that the 
population mean of the pregnant women studied had $\mathrm{Hb}$ value of $11.25 \mathrm{gldl}$, a case can be made for setting a cutoff value of $10.0 \mathrm{gldl}$ for anaemia in pregnancy among Rivers State pregnant women. In support of this notion is the fact that in many developing countries, the vast majority of women with $\mathrm{Hb}$ values around $10 \mathrm{gldl}$ are apparently healthy and symptoms free and perinatal mortality rates are no different from what they are at higher haemoglobin levels. Only haemoglobin values $<10.0 \mathrm{gldl}$ are likely to reflect inadequate maternal nutritional status with respect to iron, folic acid and other micronutrients (Rasmussen K.M 2001). A prevalence of 85.5\% was obtained in this using $\mathrm{Hb}$ values $<11.0 \mathrm{gldl}$ of which 78 (19.9) were in the first trimester of pregnancy, 126 $(30.9 \%)$ were in the second trimester and $142(34.6 \%)$ were in the third trimester. Majority of these subjects $(36.9 \%)$ were mildly anaemic, $33.5 \%$ were moderately anaemic while $15.0 \%$ were severely anaemic. However, this study found no consistent relationship between rising parity and the incidence of anaemia at booking. Perhaps, following the experience gained from the first pregnancy and the consequent increased awareness of the value of haematinics and good diet, as well as increased interaction with other pregnant women at the antenatal clinic, the effects of these may to some extent neutralize those of rising parity. This may imply that childbearing per se does not have long term detrimental effects on the woman's haematological status. This study also failed to observe any relationship between prevalence of anaemia and increasing gestational age, implying that all pregnant women were prone to anaemia throughout the gestational period, thus early booking for antenatal care would serve as an important preventive measure in pregnancy.

\section{Conclusion}

This research investigated the prevalence of anaemia among pregnant women in Port Harcourt, Rivers State. The study started with the background of the study, where the researcher emphasized on the issue that gave a reason to seek for strategies on the prevalence of anaemia among pregnant women.

The result is summarized under five chapters, chapter one consists of the background of the study, statement of the problem, aims/objectives of the study.

The second chapter dealt with review of related literature, which revealed the prevalence rate of anaemia in different parts of the world with different cut-off values of haemoglobin concentrations. The third chapter revealed the research methodology used, how the samples were collected and analyzed, population of study, area of study and data analysis which was presented in simple percentages. The fourth chapter revealed the results on the findings, which had 296 anaemic samples out of 346 samples of pregnant women studied for anaemia among attendees antenatal clinic at Braithwaite Memorial Specialist Hospital (BMSH), which gave a prevalence rate of $85.5 \%$.

Anaemia is a global epidemic with serious health crisis and continues to create social and developmental problems, particularly in Africa.

\section{Conclusion}

A total of 346 pregnant women in their different ages and varying gestational periods and parity attending antenatal clinic at the Braithwaite Memorial Specialist Hospital (BMSH) Port Harcourt were screened for anaemia using Hemocue, a non-dilution technique. The study showed that 296 (85.5\%) of the pregnant women screened were anaemic with cut-offs $\mathrm{Hb}<11.0 \mathrm{gldl}$ while 50 (14.4\%) were non-anaemic.

In all the cases screened, women at the peak of their reproductive age (30-34 years) and in their second and third trimesters of pregnancy were severely anaemic.

The present study emphasize the need for routine screening of pregnant women for anaemia from first trimester through the third trimester since early diagnosis and treatment will reduce morbidity and mortality rate.

\section{Recommendation}

This study has established that anaemia exists and poses a serious threat during pregnancy in our environment. This emphasizes the need for women to be empowered with knowledge of anaemia and its prevention, and antenatal educational programs should be included.

It is therefore recommended that:

All pregnant women should be screened for anaemia at the first antenatal visit of each pregnancy and repeatedly through the third trimester. Anaemic pregnant women should be managed in high risk antenatal clinics and routine supplementation with haematinics and prenatal vitamins is recommended.

Since anaemia in pregnancy poses a high risk factor, the prevalence rate of anaemia among pregnant women could be reduced. This could be obtained by instituting a program for the screening of pregnant women on the basis of clearly defined goals with such services as:

- Antenatal screening laboratory with strict quality control and back-up facilities.

- Education of parents on the disease and the general public. 
The reduction in the prevalence rate of anaemia among pregnant women is common if the above is followed effectively.

\section{References}

[1]. Aluka C., Amadi A. N., Kamanu C. I., Fejyi-Waboso P. A. (2001): Anaemia in pregnancy in Abia State University Teaching Hospital Aba. Journal of Medical Investigation Practice; 2: 58-61.

[2]. Amoa A. B., Klufio C. A., Kariwiga G., Heywood S. (1998): Antenatal Haemoglobin Profile at the Port Moresby General Hospital Papua New Guinea. Medical Journal; 41: 119-125.

[3]. Axemo P., Liljestrand J., Bergstrom S., Gebre-Medhin M. (1995): Aetiology of Late Fetal Death in Maputo. Gynaecology and Obstetric Investigation; 39: 103-109.

[4]. Bergsjo P., and Seha A. M. (1996): An analysis of anaemia and child mortality. Journal of Nutrition; 132: 636-645.

[5]. Buseri F. I., and Uko E. K. (2008): Prevalence and Risk Factors of anaemia Among Pregnant Women in Nigeria. The Open Haematology Journal; 2: 14-19.

[6]. Ehrlich H., merchant T. H., William Hewson. (1874): Diagnosis, Classification and Treatment of Anaemia. Journal of Complete Heamatology practice; $1: 1-88$.

[7]. Gabriel Andral. (1843): A Practical Haematology Text Book. $1^{\text {st }}$ Edition Churchill Livingstone; PP: 19-48.

[8]. Hinderaker S. G., Olsen B. E., Bergsjo P., Lie R. T., Gasheka P., Kwale G. (2001): Anaemia in Pregnancy in the Highlands of Tanzania. College of Obstetrics and Gynaecology; 80: 18-26.

[9]. Iloabachie G. C, Meniru G. I (1990): The Increasing Incidence of Anaemia in Pregnancy in Nigeria. Orient Journal of Medicine; 2: 194-197.

[10]. Jackson D. J, Klee E. B, Green S. D, Mokili J. L, Elton R. A, Cutting W. A (1991): Severe Anaemia in Pregnancy: A Problem of Primigravidae in rural Zaire. Transcript Report of Social Tropical Medical Hygiene; 85: 829-832.

[11]. Jeremiah Z. A, and Usanga E. A. (2008): Iron Deficiency and Reduced Work Capacity: A Critical Review of the Research to Determine a Casual Relationship. Journal of Nutrition; 131: 676-688.

[12]. Karl Vierordt (1852): Technical Method for Determining Anaemia. ${ }^{\text {st }}$ Edition, Cochin PP: 121-136.

[13]. Massawe S. Lindmark G, Nystron L (1996): Maternal Mortality in Tanzania-Medical Causes are interrelated with Socioeconomic and

Cultural Factors. South Africa Medical Journal; 86: 436-444.

[14]. Meda N, Mandelbrot L, Cartoux M, Dao B, Ouangre A, Debis F (1996): Anaemia during Pregnancy in Burkina Faso, West Africa: Prevalence and Associated Factors; 77:916-922.

[15]. Monica Cheesbrough (2010): District Laboratory Practice in Tropical Countries. $2^{\text {nd }}$ Edition Update Part 2; PP 305-306

[16]. Nwanukuzi E, and Mhowoli A.M (1992): The Relationship Between Asymptomatic Human Immunodeficiency Virus Infection and the prevalence and Severity of Anaemia in Pregnant Zaire women. American Journal of Tropical Medical Hygiene; 59:1004-1007.

[17]. Rasmussen K.M (2001): Is There a Casual Relationship Between Iron Deficiency Anaemia and Low Weight at Birth, Length of Gestation and Perinatal Mortality? Journal of Nutrition; 131: 5905-6035.

[18]. Ross J, Thomas E. L (1996): Iron Deficiency Anaemia and Maternal Mortality. Profile 3, Working Notes Series Number 3. Washington, D. C: Academy for Educational Development.

[19]. Saadiya A.K, Mohammed K, Javaid H.R, Sadiqua N. J, Rubina I.S (1990): Anaemia in Pregnancy - a Study of 709 Pregnant Women in Karachi. Tropical Doctor; 20: 184-185.

[20]. Shulman C.E, and Graham W. J (1996): Malaria is an Important Cause of Anaemia in Primigravidae: Evidence from a District Hospital in Coastal Kenya. Transcript of Social and Tropical Medical Hygiene; 90: 535-539.

[21]. Swammerdam (1658): Red Blood Cells and its Component, the Clinical Diagnosis of Anaemia. Journal of Obstetrics and Gynaecology; 1: 36-42.

[22]. Uko E.K, Buseri F. I, Fleming A. F (2008): Anaemia in Pregnancy in Tropical Africa. Transcript of Social and Tropical Medical Hygiene; 83: 441-448.

[23]. Urassa E, and Massawe S (1996): Anaemia in Pregnancy: A Major health Problem with Implications for Maternal Health Care. African Journal of Health Science; 3: 126-132.

[24]. Usanga E. A, Chilaka M, Archibong E. I (1994): Prevalence of Iron Deficiency Anaemia in Nigerian Pregnant Women. Journal of Medical Laboratory Science; 4: 107-113.

[25]. William Harvey (1739): Understanding Anaemia, and its Implication in Public Health. $1^{\text {st }}$ Edition PP $103-116$.

[26]. William Parry Murphy (1987): Treatment of Anaemia at the MolecularLevel. $3^{\text {rd }}$ Edition Brangalore; PP 27-34.

[27]. World Health Organization (1993): Iron Deficiency Anaemia Assessment, Prevention, and Control. A Guide for Program Managers; WHO/NHD/01.

[28]. Zucker JR, Lackritz E. M, Ruebush T.K (1994): Anaemia, Blood Transfusion Practices, HIV and Mortality among Women of Reproductive Age in Western Kenya. Transcript of Social and Tropical Medical Hygiene; 8: 173. 